\title{
Entre o mérito e a necessidade: análise dos princípios constitutivos do seguro social de doença alemão
}

\author{
Between merit and need: \\ an analysis of the underlying principles \\ in social health insurance in Germany
}

Lígia Giovanella 1

\footnotetext{
1 Núcleo de Estudos Político-Sociais em Saúde, Departamento de Administração e Planejamento em Saúde, Escola Nacional de Saúde Pública, Fundação Oswaldo Cruz. Av. Brasil 4036, sala 616, Rio de Janeiro, RJ 21040-361 Brasil.
}

\begin{abstract}
A bstract This article describes and analyzes the structural principles of social health insurance in Germany and discusses their interrelations and current form. Focusing on salaried work, social security in Germany links rights and duties to the place occupied by workers in the production process and maintains a differentiation in their status. As a paradigm of social security, citizens' social rights in Germany are organized according to princi ples of equivalence, subsidiarity, and solidarity. The coexistence of these contradictory principles generates a constant field of tension and conditions their effect, thus mediating how each one is implemented. This tensi on, which has al ways existed in the underlying system, is reedited each time the political context changes. While subsidiarity and equivalence prevailed in the original social security system, the solution to the conflict tended towards solidarity during the expansion of welfare states and social health insurance. At present, however, there is a call for reediting subsidiarity and equivalence.
\end{abstract}

Key words Social Security; Health Policy; Public Policy

Resumo O artigo visa à descrição e análise dos princípios estruturais do seguro social de doença alemão, à discussão de suas inter-relações e da forma atual de vigência dos mesmos. Centrada no trabalho assalariado, a proteção social alemã vincula direitos e deveres à si tuação ocupada pel os trabal hadores na produção, preservando status diferenciados. Paradigmática do modelo de seguro social , a cidadania social alemã organiza-se segundo os princípios da equivalência, subsi diariedade e soli dariedade. A convivência desses princípios contraditórios gera um campo de tensão constante e condiciona a vigência dos mesmos, medi ando a operaci onalização de cada um. Essa tensão, sempre existente na base do sistema, reatualiza-se a cada conjuntura. Se a subsidiariedade e equivalência prevaleceram na origem do seguro social, a solução do conflito tendeu para a solidariedade no período de expansão dos welfare states e do seguro social de doença. Atualmente, porém, apela-se para a reatual ização da subsi di ari edade eda equivalência. Palavras-chave Previdência Social; Política de Saúde; Política Social 


\section{Introdução}

O seguro social de saúde alemão - Gesetzli che Krankenversicherung - GKV - é parte de amplo sistema de proteção social, com o qual compartilha princípios e características básicas. $\mathrm{Na}$ Alemanha, a proteção social é garantida especialmente através do seguro social, que é composto por cinco ramos de seguro: vel hice, invalidez e morte (previdência), doença, desemprego, acidentes de trabal ho e cuidados de longa duração. A proteção social alemã é mais ampla do que o seguro social. Complementada pela assistência social, assegura renda mínima mediante a comprovação de carência por testes de meios. À proteção social poder-se-ia ainda somar toda a regulação do mercado de trabalho, as medidas para promoção do trabalho e incentivos ao aprendizado de outras profissões, assim como a legislação especial para proteção e garantia de trabalho de deficientes.

O seguro social de doença garante a proteção ao risco de adoecer de forma inclusiva e abrangente, embora, assim como os outros ramos do seguro, seja centrado no trabalho assalariado. Cobre $90 \%$ da população e seu catálogo de ações médico-sanitárias é completo: inclui atenção médica ambulatorial e hospitalar em todos os níveis de atenção, assistência farmacêutica, odontológica e psicoterápica, entre outras. Além dessas ações, o seguro doença abrange, entre seus benefícios, o auxílio-doença, ou seja, a continuidade do pagamento de salários em caso de doença.

O presente artigo tem por objetivo a descrição e a análise dos princípios estruturais do seguro social de doença alemão em sua trajetória histórica e a discussão não só de suas inter-relações e condicionamentos mútuos, como também da contemporaneidade e forma de vigência dos mesmos. A discussão desses princípios pode contribuir para uma melhor compreensão da política social brasileira e subsidiar a análise de reformas do sistema brasileiro de proteção social em geral e da proteção à saúde em particular, pois os princípios constitutivos do seguro social alemão são em parte compartilhados pela proteção social brasileira. Subsidiaridade, solidariedade e equivalência são princípios incluídos no capítulo Da Ordem Social da Constituição Federal de 1988.

Inicialmente, serão abordadas as características do seguro social e identificados seus princípios constitutivos. Em seguida, serão analisadas as concepções de equivalência, solidariedade e subsidiariedade, para, então, efetuarse a discussão relativa à forma atual de vigência destes princípios. Ao final, serão levantadas questões acerca tanto do significado tendencial das últimas leis de contenção de gastos do seguro social de doença - caso a reforma se concretize plenamente -, quanto da importância dos princípios estruturais para a estabilidade do modelo de seguro social.

Em seguida, serão descritas as características do seguro social e identificados os princípios básicos que o regem.

\section{Características do modelo de proteção} social alemão

A organização do Estado de Bem-Estar alemão é paradigmática de um dos tipo-ideais de caracterização dos sistemas de proteção social modernos: meritocrático-corporativo (Titmuss, 1958), conservador (Esping-Andersen, 1990) ou de seguro social (Fleury, 1994; Werneck Vianna, 1991).

A gênese e a estrutura do sistema de seguro social alemão estão intimamente ligadas ao conflito capital-trabalho. Na Alemanha, durante o processo conservador de transição para o capitalismo, o Estado autoritário tomou para si a responsabilidade pela segurança social e incluiu gradualmente a população dependente do trabalho assalariado na solidariedade obrigatória.

Criado por Bismarck ao final do século passado, o seguro social alemão dirigia-se a um grupo que, embora crescente e economicamente importante, representava ínfima parcela da população: os trabalhadores assalariados. A política social de Bismarck, para além do enfrentamento da questão social, conformou uma proposta intencional de organização corporativa da sociedade - corporações submetidas ao Estado - e de ampliação do controle social. Buscou combater o avanço da socialdemocracia mediante a "realização dos pontos das rei vindi cações social istas, que (fossem) sejam adequados e compatíveis com as leis do Estado e da soci edade" (Bismarck apud Oliveira, 1995:25). Por conseguinte, a introdução do seguro social sofreu forte oposição dos trabal hadores.

Centrado na esfera do trabalho assalariado, o Estado de seguro social assegurou direitos sociais aos cidadãos na medida de sua participação no mercado de trabal ho, da mesma forma que no caso da nossa "cidadania regulada" (Santos, 1979), segundo a qual os direitos do cidadão restringiam-se aos direitos do lugar ocupado pelo indivíduo no processo produtivo.

Ao condicionar direitos ao mérito individual, o seguro social consolida grupos com di- 
ferentes status e privilégios. A necessidade de ajuda é avaliada como merecida ou imerecida, cristalizando-se diferenças sociais com suas respectivas conotações morais (Koch, 1995:81).

A centralidade da política social no mundo do trabalho assalariado caracteriza-se de três maneiras, de acordo com o direito a benefícios sociais: "é dependente de trabal ho assalariado anterior; pressupõe di sposi ção para o exercício detrabal ho assalariado; e o valor dos benefícios é definido segundo os rendimentos do trabalho" (Nullmeier \& Vobruba, 1995:12).

Esta ênfase no trabalho assalariado faz com que princípios norteadores das relações de trabalho sejam transpostos para a base da política social. A concepção de que o mérito/remuneração de cada indivíduo corresponde à qualidade e extensão de sua produção torna-se fundamento do sistema de seguro social. No mercado de trabalho, a remuneração corresponderia à capacidade de produção de cada indivíduo. No seguro social, os benefícios seriam correspondentes à sua capaci dade de contribuição.

A maioria das formas de promoção de eqüidade no seguro social, em virtude da centralidade no trabal ho assalariado, está vinculada à integração no mercado de trabal ho. Contudo, as regras de limite máximo para desconto da contribuição e para obrigatoriedade de participação nos seguros, assim como a não obrigatoriedade de seguro para trabalhos de baixos salários - a chamada ocupação mínima -, quebram essa vinculação na parte superior e inferior do mercado de trabalho (Nullmeier \& Vobruba, 1995:15). Os assalariados de alta remuneração são liberados da solidariedade coercitiva, e os trabalhadores com baixa integração trabalho de tempo parcial com remuneração mínima - são punidos, expulsos/ excluídos da solidariedade.

Como a cidadania social é regulada pela inserção no processo produtivo, o "processo de inclusão" (Offe, 1990) não é antagônico à exclusão, mas sim concomitante. Um sistema de seguro social, ao mesmo tempo em que assegura transferências e serviços baseados em determinados direitos justificados, constrange a garantia desses direitos àqueles que não preenchem os requisitos: “Cada inclusão é acompanhada por uma exclusão (Luhmann), pois cada programa social condicional é construído segundo o esquema 'se-então', no qual a negação 'se não-então não' está implícita” (Offe, 1990: 185s).

O desenvolvimento posterior do seguro social foi de inclusão e expansão progressivas. No processo de expansão, tanto foram incluídos progressivamente novos setores da população, como foram ampliados os benefícios e serviços cobertos. Houve o reconhecimento cumulativo de necessidades a serem garantidas - doença (1883), acidentes de trabalho (1885), velhice (1891), desemprego (1927) e cuidados de longa duração (1994). Ampliou-se o círculo de beneficiários com a inclusão de novos grupos profissionais, expandindo-se a proporção de segurados na população total, e o nível de renda ea abrangência da cesta de serviços afiançados por cada ramo cresceram gradualmente (Alber, 1982:64).

A história do seguro social alemão, além da expansão e inclusão progressivas, é também marcada pela estabilidade do modelo de seguro social. O sistema criado demonstrou alta estabilidade, mantendo sua estrutura básica durante mais de cem anos. Sobreviveu - saiu ileso - à queda do império, à jovem e tumultuada república de Weimar, à inflação de 1923 e à grande depressão do início dos anos 30, ao nazismo (Terceiro Reich), bem como à derrota nas duas guerras mundiais deste século. E, até o momento, tem sobrevivido ao neoliberalismo.

O sistema de seguro social alemão tem como características gerais: a participação compulsória dos trabalhadores assalariados mediante contribuições proporcionais aos salários até certo limite máximo definido por lei; a participação paritária dos empregadores nas contribuições na maioria de seus ramos e a administração autônoma dos órgãos de seguro, os quais são, em geral, geridos de forma paritária pelos trabal hadores e empregadores. Os órgãos de seguro são públicos, mas não estatais, e sua atuação é regulada e controlada pelo Estado.

\section{Os princípios estruturais do seguro social}

O seguro social constitui-se com base nos princípios de equivalência - por ser um seguro -, de solidariedade - por pressupor alguma redistribuição - e de subsidiariedade - por conseguinte, a ação estatal deve ser complementar. Pelo princípio de equivalência, os benefícios são vinculados às contribuições prévias, e são conformadas diversas instituições dirigidas a distintos grupos de trabalhadores. O princípio da subsidiariedade, por influência da igreja, serve para enfatizar que o Estado somente interferirá quando a capacidade da família estiver exaurida, envolvendo responsabilidade de cada indivíduo. O princípio da solidariedade torna as contribuições proporcionais à renda e os benefícios de acordo às necessidades, produzindo redistribuição. 
Em cada um dos ramos do seguro social, os princípios estruturais desse modelo de proteção manifestam-se de forma diferente. Sua implementação distingue-se conforme as especificidades das atribuições de cada ramo e a ascendência de um sobre os outros é diversa. Isto é, embora os três princípios estruturem o sistema, o predomínio de um sobre os outros em determinado ramo do seguro social é diferenciado.

Nos seguros previdenciário, de desemprego e de acidentes, a maioria dos benefícios é garantida segundo o princípio de equivalência a extensão dos benefícios depende do valor das contribuições. Há certa correspondência entre benefícios e contribuições. Por sua vez, nos seguros doença e de cuidados de longa duração predomina o princípio de solidariedade: os segurados, com poucas exceções, têm direito ao mesmo catálogo de serviços, independente do valor das contribuições. Além disso, a administração autônoma - assim como a ênfase no trabalho assalariado e a definição inicial do asseguramento apenas aos operários industriais tem como base o princípio da subsidiariedade: a intervenção estatal na proteção social deve ser subsidiária, complementar. Na realidade, o princípio da subsidiariedade manifesta-se com toda força na assistência social, na qual os benefícios são assegurados somente quando o indivíduo e sua família não estão em condições de suprir suas necessidades básicas por meios próprios.

As principais características do seguro social de doença são expressões mediadas destes princípios. O direito à utilização conforme as necessidades, sem relação com o valor das contribuições, e o acesso direto às ações e serviços de saúde, sem pagamento por parte dos segurados - Sachsl eistungsprinzi p -, são expressões do princípio de solidariedade. A pluralidade de Caixas organizadas por profissão, ramo de produção, região ou empresa e a definição do valor monetário do auxílio-doença correspondente ao salário de contribuição expressam o princípio de equivalência. Além disso, o apelo à responsabilidade dos indivíduos sobre a própria saúde apóia-se no princípio de subsidiariedade.

Os princípios de equivalência, solidariedade e subsidiariedade, estruturantes do seguro social de saúde, analisados a seguir, têm vigência desde a sua criação, expressando-se com diferentes ênfases no transcorrer do tempo.

\section{1) Equivalência}

O princípio básico regente de qualquer seguro é a equivalência. Segundo este princípio, o volume e a extensão dos benefícios deve ser equivalente ao valor das contribuições individuais: o valor dos benefícios recebidos deve corresponder ao valor das contribuições pagas pelo segurado.

Em qualquer tipo de seguro, a probabilidade matemática de o dano vir a afetar um indivíduo e o valor monetário do benefício correspondente ao valor do prêmio pago pelo segurado são calculados sob os pressupostos de grande número de segurados para mesmo tipo de risco, a aleatoriedade da entrada dos casos de seguro e sua independência. A possibilidade de estimativa dos riscos permite o cálculo das contribuições a serem pagas pelos segurados a fim de que estas sejam suficientes para cobrir as necessidades estimadas, com base no princípio de equivalência.

O seguro individual representa uma resposta a possibilidades de danos que ameaçam a empresa ou o indivíduo e que colocam em questão a ação utilitarista máxima de cada um, visto enquanto homo economicus. O benefício de um seguro privado é, em geral, a garantia de compensação financeira no caso de o indivíduo sofrer o dano assegurado. Talvez, mais importante que a restituição financeira, seja a criação da expectativa de segurança: a redução do desconhecimento a respeito das conseqüências do perigo. Quer dizer, o benefício do seguro também é bem de informação sobre o futuro de certo objeto de valor (Lauer-Kirschbaum \& Rüb, 1994:44).

O seguro social, por sua vez, reduz a insegurança social através da compensação de riscos politicamente definidos. A especificidade do risco no seguro social consiste no reconhecimento político de situações de vida como provocadas pela insegurança social - produção social objetiva dos riscos - e a vinculação das mesmas ao direito a benefícios sociais estatais (Lauer-Kirschbaum \& Rüb, 1994:44).

Na organização da sociedade industrial capitalista, os indivíduos encontram-se submetidos a variados riscos inerentes a ela, cujas origens não podem ser atribuídas a comportamentos individuais inadequados, o que torna pouco plausível que os atingidos possam enfrentar e superar isoladamente o seu destino físico e material. Além disso, apenas pelo lado da discussão da questão dos riscos - sem entrar aqui na análise sobre origem e determinações da política social, que não são objetos deste artigo -, o enfrentamento coletivo dos 
riscos decorre de suas conseqüências negativas coletivas, seus custos externos (Offe, 1990). Ocorre, assim, o reconhecimento dos riscos e de suas formas de enfrentamento pelo Estado central, levando-os a integrar a sua agenda.

O princípio da equivalência decorre não apenas da lógica de seguro, mas também da transposição de princípios regentes das relações de trabalho para a política social. Embora a remuneração do trabalho seja conforme o vaIor mínimo necessário para sua reprodução e não de acordo com o valor produzido/ agregado, existe certa correspondência entre a remuneração e a quanti dade de trabal ho realizado. Desse modo, a concepção de que há relação de equivalência entre a quantidade de trabalho realizado pelo indivíduo e sua remuneração correlaciona-se à acepção, no seguro social, de que os benefícios devem corresponder às contribuições.

Ao mesmo tempo, o princípio de equivalência evita o gozo de benefícios por pessoas não autorizadas pelas contribuições, garantindo apoio ao modelo de proteção quando prevê que o nível de benefícios deve ser correspondente às contribuições. Previne a redistribuição interna proposital entre os participantes de maior e menor renda. A redistribuição que de fato ocorre no interior da comunidade de segurados não pode ser conhecida com antecipação, pois isto viria a corroer a legitimidade do sistema (Offe, 1990).

Entretanto, no seguro social, a equivalência entre contribuições e benefícios é rompida com a finalidade de compensação social. A vigência concomitante da solidariedade restringe o exercício da equivalência. Contribuições e benefícios estão relacionados aos salários, contudo não há equivalência imediata entre ambos. O segurado não recebe de volta o valor de sua conta individual de contribuições capitalizada no transcorrer dos anos. Uma necessidade básica de manutenção do padrão de vida merecido pela sua participação no mercado de trabalho, conquistado durante sua vida produtiva - é definida politicamente.

A previdência social é o ramo do seguro social alemão em que a equivalência tem maior importância. A fórmula para cálculos de aposentadoria é apresentada como expressão da configuração de benefícios equivalentes às contribuições. Porém, entre a contribuição e o vaIor da aposentadoria não há relação constitutiva direta. A posição que o segurado ocupa na hierarquia de renda justifica o valor da participação individual no volume financeiro colocado posteriormente à disposição, o qual, por sua vez, é determinado conforme algum objetivo de segurança social (Kolb, 1985, apud Nullmeier \&Vobruba, 1995:16).

O nível do salário de contribuição a que devem corresponder as transferências financeiras dos diversos ramos do seguro social tem por base não apenas o mérito, mas também certa concepção de necessidade a ser suprida, que é, por sua vez, politicamente definida (Nullmeier \& Vobruba, 1995). Por conseguinte, está presente uma concepção de garantia de direitos conforme a necessidade - Bedarfsgerechtigkeit nos diversos ramos do sistema, entre outros: assistência médica completa em caso de doença, garantia do padrão de vida em níveis reduzidos no seguro-aposentadoria após o cumprimento do tempo de trabalho - $68 \%$ em aposentadoria padrão após 45 anos de seguro - e no seguro-desemprego - $60 \%$ no seguro-desemprego e 53\% no auxílio-desemprego. Pode-se, portanto, denominar este princípio como de equivalência mediada.

No seguro social de doença, a solidariedade suplanta a equivalência, desvinculando o direito à atenção do valor das contribuições. Neste ramo do seguro social, o princípio de equivalência vige apenas para o auxílio-doença, correspondendo à determinada proporção dos salários de contribuição. É uma equivalência igualmente mediada, pois os benefícios não correspondem diretamente ao valor das contribuições, uma vez que as transferências não têm por base fundos individuais capitalizados e o nível de reposição salarial em caso de doença é definido politicamente.

Originalmente, o princípio de equivalência tinha maior significado também para o seguro social de saúde em virtude da maior participação das transferências financeiras no conjunto de gastos. Embora o pagamento de benefícios em espécie, especialmente o auxílio-doença, permaneça como encargo do seguro social de doença, sua importância diminuiu no transcorrer dos anos tanto relativamente, por causa da expansão do catálogo de ações médico-sanitárias, como para a definição das transferências financeiras (Arnold, 1993:28). Em razão de mudanças na legislação, passaram a fazer parte do seguro social benefícios sem relação com contribuições - em particular, os relativos à política familiar e à maternidade.

No debate atual, o apelo ao princípio de equivalência no seguro social de doença serve para a defesa da exclusão desses últimos benefícios, tidos como estranhos ao seguro - Fremdleistungen. Estes seriam da competência estatal direta e deveriam ser financiados com recursos fiscais, aliviando o caixa dos órgãos de administração autônoma dos seguros sociais. 
Ainda que, na sociedade capitalista, uma certa equivalência venha a ser inevitável, é importante não esquecer que o nível a partir do qual ela deve vigorar é politicamente definido. O ponto de equilíbrio entre equivalência e necessidade constitui objeto de constante disputa.

\section{2) Solidariedade}

Diversos significados e empregos são atribuídos à solidariedade: não é apenas preceito moral; é palavra de ordem, é vínculo de classe, é promessa de segurança burguesa e é justificativa para a redistribuição que ocorre no interior do seguro social. O princípio da solidariedade, ao contrário do de equivalência, significa que o ônus de cada um deve ser redistribuído dentro de uma comunidade solidária e não que cada grupo de risco deva acumular reservas de capital, disponíveis para cobrir danos futuros.

A palavra solidariedade origina-se de sólido (em latim solidum), o que lhe imprime um sentido de estar sobre bases firmes. Estar com outros na mesma situação, ter interesses comuns. A expressão do senso comum que talvez meIhor defina solidariedade seja: “um por todose todos por um" (Schönig, 1996:101). Nesta sentença, solidarizar-se significa colocar-se conscientemente no lugar do outro. Identificar-se com o destino do outro. O que acontece ao outro é experimentado como se tivesse ocorrido a cada um. O indivíduo se identifica com o grupo e o grupo se identifica com o indivíduo (Baumgartner, 1997:30). Assim, solidariedade é relação de responsabilidade entre pessoas unidas por interesses comuns, de maneira que cada elemento do grupo sinta a obrigação moral de apoiar os outros.

Enquanto princípio moral na tradição judaico-cristã, a solidariedade vincula o indivíduo a uma comunidade fundamental, na qual todos - homens e mulheres - são portadores de dignidade pessoal em virtude de serem criados por Deus à Sua imagem e semelhança (Baumgartner, 1997:30). Nessa tradição, como tal princípio advém da comunhão de pertencimento à comunidade humana de seres dignos, recebe val or universal. Refere-se a todos os seres humanos, valendo para toda situação em que a realização de vida digna esteja obstaculizada.

Na tradição socialista, a solidariedade provém do pertencimento à mesma classe social. É o interesse comum de classe que imprime a cada um a obrigação moral de responsabilizarse pelo destino do outro. Este é o sentido em que o termo solidariedade foi empregado nas lutas dos trabalhadores no século passado, enquanto solidariedade de classe social. Nesta acepção, o reconhecimento de um 'nós' inclusivo - de um 'estamos no mesmo barco' - e a identificação com o destino do outro são decorrências do pertencimento comum de classe.

Ao final do século passado, essa solidariedade espontânea de classe expressava-se em Caixas autônomas de ajuda mútua organizadas pelos trabalhadores que foram incorporadas na legislação social. Por isso, alguns autores referem-se a uma solidariedade coercitiva em razão de a filiação ao seguro social ser legalmente obrigatória e ter substituído iniciativas próprias dos trabalhadores (Koch, 1995). A solidariedade teria nesta acepção duas facetas. Uma, coercitiva, imposta pelo sistema de seguro social. Outra, espontânea, de classe, democráti$\mathrm{ca}$ política, exercitada pelos trabal hadores.

É com sua institucionalização nos diversos ramos do seguro social que o princípio de solidariedade vem a ser implicitamente definido. Operacionalmente, para o seguro social como um todo, o princípio da solidariedade é vínculo que responsabiliza cada segurado pelos encargos do conjunto. Significa que o ônus de cada um deve ser redistribuído no interior de uma comunidade solidária (Schulemburg, 1990:317).

Em virtude da centralidade no trabalho assalariado, o seguro social tem por base a solidariedade de grupo. Os grupos são constituídos de modo mais ou menos homogêneo. Definem-se conforme a posição ocupada na produção, excluindo-se do seguro obrigatório as remunerações muito altas e muito baixas. Desse modo, o princípio da equivalência condiciona a solidariedade e esta se exerce de forma partida. Essa forma de segmentação na garantia da cidadania social - segundo a inserção no mercado de trabalho - é característica do modelo de seguro social. Neste modelo, a redistribuição ocorre tipicamente apenas entre os integrantes de mesmo grupo ocupacional. Tradicionalmente, a inclusão no seguro social distinguiu operários de empregados e trabal hadores dos diversos ramos da produção. Estes estariam submetidos a diferentes riscos e deveriam formar grupos distintos.

A conformação de grupos com certa homogeneidade, tendo como finalidade facilitar o exercício da solidariedade grupal, seria a justificativa para a exclusão de grupos de assalariados com remunerações muito altas e muito baixas, tal como para a definição de nível máximo de renda para as contribuições obrigatórias. Assim, o apelo a contribuir solidariamente não tensionaria demais os interesses individuais e não afetaria a coesão do grupo. Essas exclusões evitariam que a disposição dos indi- 
víduos de maior renda para a solidariedade fosse sobredistendida.

O significado do exercício da solidariedade modificou-se no processo de expansão do seguro social. Inicialmente, a comunidade solidária era entendida como composta por um grupo de indivíduos de mesma camada social, os operários industriais. Atualmente, a redistribuição se dá entre diferentes estratos sociais.

Esta evolução da proteção social da Alemanha subentende a ampliação da solidariedade de grupo, uma vez que tanto os grupos tornaram-se cada vez mais abrangentes, como o financiamento por meio de recursos fiscais adquiriu maior importância com o passar do tempo.

O seguro social de doença é o ramo do seguro social em que o princípio da solidariedade adquire maior importância. Enquanto nas outras áreas do seguro social vigora uma equivalência mediada pela solidariedade, no seguro social de saúde impera o princípio da necessidade, o que o torna um sistema cunhado pelo princípio da solidariedade. Os segurados recebem assistência na medida de suas necessidades de saúde e contribuem de acordo com sua capacidade financeira. Idade, sexo, risco de adoecer, estado de saúde e composição familiar não são levadas em conta no cálculo das contribuições.

As contribuições dos segurados - enquanto proporção de seus salários - são dependentes de suas possibilidades financeiras. O direito à atenção conforme a necessidade é independente do valor das contribuições, isto é, da capacidade de financiamento de cada indivíduo (Nullmeier \& Vobruba, 1995:21).

Apesar de a proteção à saúde ser solidária e abrangente, é necessário relembrar que a solidariedade é restrita aos integrados ou àqueles com disposição para participar no mercado de trabalho. Além disso, nem toda a população empregada é obrigatoriamente assegurada.

A vigência do princípio da solidariedade produz redistribuição no interior do seguro social de doença. Contribuições proporcionais à renda e direito a benefícios correspondentes às necessidades levam a efeitos distributivos para muito além das técnicas de seguro de compensação de riscos. Entre os incluídos, os trabalhadores em melhor situação financeira contribuem para a satisfação das necessidades dos economicamente mais fracos. Os sadios ou os que adoecem menos freqüentemente pagam para os doentes; os segurados sem dependentes, para os segurados com dependentes; e, por fim, os mais jovens, para os mais velhos. Embora esta redistribuição seja preferencialmente horizontal, isto é, ocorra no interior de mesma "comunidade" de trabalhadores submetidos a certos riscos comuns, também é vertical quando é feita daqueles que recebem melhor remuneração para os que obtêm pior remuneração, mas não se realiza diretamente entre os grupos mais bem remunerados e aqueles em pior situação econômica. A redistribuição efetua-se com primazia entre os grupos com baixo risco de adoecer e maior remuneração e aqueles com alto risco de adoecer e baixa renda.

É igualmente uma redistribuição entre jovens e velhos - o chamado contrato intergeracional. O seguro social de saúde dos aposentados é deficitário. A receita das contribuições pagas por aposentados (50\%) e pela previdência social (50\%) - correspondente ao que seria o encargo dos empregadores - não é suficiente para cobrir as despesas com saúde dos aposentados. Uma parte das contribuições dos trabaIhadores ativos - equivalente a cerca de três pontos percentuais - financia o déficit do seguro social de doença dos aposentados (Oldigen, 1994:73). Além disso, a redistribuição de renda no seguro doença também se processa dos segurados sem dependentes para os segurados com dependentes sem rendimentos, já que vigora uma compensação sobre o peso da família.

Tradicionalmente, esta redistribuição foi restrita ao interior do grupo de segurados de cada Caixa de Doença - Krankenkasse-, organizadas por ocupação, região ou empresa e com adscrição compulsória de clientelas. Todavia, a partir de 1993, a redistribuição foi ampliada para o conjunto do sistema pela Lei da Estrutura da Saúde. Com o intuito de introduzir a competição entre as Caixas, esta lei ampliou a liberdade de escolha das Caixas pelo trabal hador. A liberdade de escolha, anteriormente restrita a certos grupos ocupacionais, foi estendida para a maioria dos segurados. Ao mesmo tempo, com o intuito de evitar uma competição predatória, foi criado um mecanismo de transferências financeiras entre as Caixas, objetivando a compensação da estrutura diferenciada de riscos de seus segurados.

Por meio deste mecanismo, a redistribuição rompeu os limites da comunidade de segurados de cada Caixa, o que levou à redução da amplitude das diferenças existentes entre as taxas de contribuição das diversas Caixas. As taxas de contribuição, até então, eram bastante diferenciadas, em virtude da adscrição compulsória de segurados a distintos tipos de Caixas, conforme sua inserção no processo produtivo.

Para Offe (1990:181), a redistribuição que ocorre no âmago do sistema é não intencional. 
A redistribuição que ocorre entre pessoas sadias e doentes, entre necessitados de terapias mais caras e mais baratas, entre famílias com e sem crianças, entre pessoas que morrem cedo e que vivem mais, não é estrategicamente desejada. Os efeitos de redistribuição decorrem de circunstâncias naturais da existência humana, são contingentes.

Os segurados reconhecem a validade da redistribuição que ocorre no interior do sistema expressão do princípio de solidariedade. Pesquisas de opinião e análises qualitativas têm demonstrado que o efeito redistributivo em favor dos mais idosos, doentes crônicos e familiares dependentes é desejado pelos segurados (SVR, 1994; Ulrich et al., 1994; Braun, 1995; Rinne \& Wagner, 1995). A aceitação da redistribuição, porém, não decorre sobretudo do alto valor atribuído à solidariedade. As justificações normativas para a solidariedade têm papel subordinado para a aceitabilidade do sistema. Cálculos comuns, não financeiros, de interesse individual é que garantem a aceitabilidade do sistema (Ulrich et al., 1994). Trata-se de um cálculo de interesse intertemporal que torna aceitável o sistema solidário: a expectativa de utilização e a confiança na garantia de atenção futura.

Embora poucos sejam os que se consideram na posição de favorecidos pela redistribuição, ou seja, conquanto a grande maioria dos entrevistados assuma a posição de quem paga pela redistribuição, esta posição é avaliada de modo positivo. A garantia da possibilidade de uso segundo o princípio da necessidade, na qual os segurados incluem suas expectativas de utilização futura, torna a redistribuição aceitável (Ulrich et al., 1994:356). A compensação é estar sadio e o fator tempo exerce aí papel fundamental. O sistema garante a reciprocidade no caso de mudança de posição em razão da expectativa de maior utilização futura. Quanto mais idoso for um indivíduo, maior será sua necessidade de atenção, havendo assim a perspectiva de redistribuição intertemporal em benefício de cada um.

Considerar a redistribuição pelos segurados como primariamente intertemporal - da juventude para a velhice - mais do que interpessoal, bem como não desejar a mudança de posição - ninguém deseja ficar doente para utilizar mais serviços - , faz com que a posição de pagante-líquido (avaliam que pagam mais do que gastam com a utilização) seja apreciada como positiva (Ulrich et al., 1994:370).

Os segurados têm confiança na estabilidade da garantia de proteção em situações futuras que ultrapassem sua capacidade de pagamento. Valorizam positivamente suas expe- riências de utilização e levam em conta que, no futuro, a atenção da qual necessitarem estará garantida, demonstrando alta satisfação com o sistema solidário (SVR, 1994; Ulrich et al., 1994; Braun, 1995; Rinne \& Wagner, 1995). Para a maioria dos segurados, o sentimento de segurança baseia-se na forma de organização do sistema, tida como a mais adequada para o asseguramento do risco de doença: um sistema obrigatório e solidário - a futura utilização não está vinculada à capacidade de financiamento de cada um e dependerá da necessidade.

\section{3) Subsidiariedade}

Outro dentre os princípios básicos do seguro social de doença, segundo o Código Social alemão - Sozialgesetzbuch - , é o princípio de subsidiariedade. Segundo este, a responsabilidade primeira pela saúde é do indivíduo e de sua família. O Estado deve tomar a seu encargo apenas aquilo que os indivíduos ou famílias não estão em condições de garantir: “a compensação solidária deve ser uma ajuda para a autoajuda" (BMAS, 1994:140).

O quinto livro do Código Social, que trata especificamente do seguro social de doença, apela para a responsabilidade própria dos segurados: “Os segurados são co-responsáveis por sua saúde. Eles devem contribuir para a prevenção das doenças e da incapaci dade e a superação de suas conseqüências, através de uma conduta de vida conscientemente saudável euma participação precoce em medidas preventivas, bem como através da cooperação ativa no tratamento das doenças e na reabilitação" (BRD, 1993:109).

A vigência do princípio de subsidiariedade no seguro social de doença significa que os riscos dos custos da doença somente devem ser garantidos por uma comunidade solidária maior quando o indivíduo ou sua família por si mesmos não estiverem em condições de superar o risco. Este princípio justifica a definição de limite máximo de renda para a obrigatoriedade de participação no seguro social. Quem recebe acima de determinada quantia, delimitada por lei, deve prover por seus próprios meios, privadamente, a sua proteção mediante a compra de seguro privado ou da formação de poupança.

No decorrer de mais de cem anos de história do seguro social de saúde, o princípio da subsidiariedade foi perdendo força na estruturação do sistema. Originalmente, este princípio tinha maior importância, pois o grupo de segurados obrigatórios era pequeno e a extensão dos benefícios era baixa. Com a ampliação 
do catálogo de ações médico-sanitárias e a inclusão de parcela cada vez maior da população, seu significado foi passando de modo gradual para segundo plano (Schulemburg, 1990: 315).

A subsidiariedade perdeu importância em razão da incorporação de novos ramos de serviços e ações que tradicionalmente estavam a cargo da família. Os cuidados dispensados aos velhos, por exemplo, tradicionalmente quase que restritos à comunidade familiar, foram assumidos progressivamente pelo seguro doença até 1994, quando foi criado novo ramo do seguro social: o seguro social de cuidados de longa duração - Pflegeversi cherung -, que assegura cuidados domiciliares e asilares, sobretudo para idosos. Este caso exemplifica de modo claro uma necessidade que anteriormente era coberta apenas de forma subsidiária e que foi incorporada pela solidariedade.

No momento presente, é na assistência social que vigora integralmente o princípio da subsidiariedade. A assistência social - na verdade, externa e complementar ao sistema de seguro social - elucida bem o princípio da subsidiariedade: apenas quando o indivíduo e sua família estão impossibilitados por seus próprios meios é que o Estado pode intervir.

O princípio de assistência pressupõe financiamento fiscal sem contribuições diretas dos beneficiários, mas o auxílio só se concretiza pela comprovação da carência. Uma prova da necessidade é decisiva para o direito ao benefício e para definir o tipo e a extensão da assistência social, a qual é ajuda individualizada, ajustada à situação de cada caso e deveria ser, ao mesmo tempo, subsidiária: complementar à ajuda própria e ao auxílio dos familiares (Frerich, 1996:35).

Em virtude da ampla cobertura e da extensão do catálogo de ações, o princípio da subsidiariedade não caracteriza a prática atual do seguro social de doença. Entretanto, esta definição está hoje no centro da argumentação por políticas de contenção. No debate atual, alguns autores chegam a questionar se a grande maioria da população coberta pelo seguro social de doença é, de fato, necessitada de proteção (Schulemburg, 1990).

A reatualização contemporânea do significado de subsidiariedade justifica uma breve recuperação do debate sobre este princípio. O seu significado ainda é objeto de controvérsia e sua discussão tem assumido diferentes ênfases.

Na Alemanha, o debate sócio-político sobre a questão da subsidiariedade mantém sua vitalidade há mais de um século (Deppe, 1985; Sachsse, 1994). Tal debate tem adquirido im- portância reiteradamente em períodos de crise ealtos índices de desemprego (Deppe, 1985), e, desde os anos 80, com a coalizão liberal conservadora no poder, tem sido evocado como fundamento para a maioria das reformas conservadoras.

As mais diferentes discussões acerca da ordem política deixam-se subsumir ao termo subsidiariedade: debates sobre a relação entre auto-responsabilidade e regulação estatal, assistência social pública e beneficente, pequenas redes sociais e grandes organizações burocráticas.

No que diz respeito ao seguro social, sua preponderância inicial explica o caráter restritivo do sistema: a pouca abrangência do grupo de segurados e os benefícios estritos. Desde o início, a discussão sobre subsidiariedade desenvolve-se segundo duas linhas principais de interpretação: uma, de caráter liberal - de defesa da livre iniciativa -, e outra, de maior influência na implementação deste princípio na Alemanha, advinda da doutrina social católica.

Uma das raízes do princípio de subsidiariedade encontra-se no pensamento liberal dos séculos XVIII e XIX (Sachsse, 1994:718), segundo o qual, a sociedade era concebida como autônoma: uma sociedade de trocas auto-reguladas pelas leis de mercado, na qual o indivíduo sujeito livre de qualquer coerção e auto-responsável - socializa-se. O Estado, concebido como esfera distinta da sociedade e responsável pelo exercício legítimo da violência, teria essencialmente como tarefa a garantia das condições gerais de sociabilização - Vergesell schaftung - da sociedade de trocas. A garantia da existência deveria ser deixada à iniciativa própria do indivíduo, porque, na concepção liberal, a reprodução pertence à esfera privada, é responsabilidade primária do indivíduo. A responsabilidade do Estado deveria ser restrita apenas a situações excepcionais, nas quais o indivíduo não consegue garantir sua existência por seus próprios meios, suprindo suas necessidades no mercado. Ou seja, a atuação do Estado deveria ser subsidiária, o que garantiria a liberdade individual (Sachsse, 1994).

Como a ajuda é subsidiária - quer dizer, é complementar, vem em segunda linha -, a necessidade tem que ser comprovada. A subsidiariedade legitima os chamados testes de meios como condição de elegibilidade para acesso aos benefícios. Este princípio - que seria para os liberais, antes de tudo, defesa da esfera privada, da liberdade individual - é que permite a intromissão, por vezes drástica, do Estado na vida privada dos indivíduos (Deppe, 1985:85). 
Em síntese, na tradição do pensamento social liberal, subsidiariedade refere-se a uma distribuição da responsabilidade social entre indivíduo, comunidade e Estado, em que a autoresponsabilidade individual tem precedência sobre a proteção e a segurança estatais (Sachsse, 1994:718).

A outra linha de interpretação do princípio de subsidiariedade está no pensamento social católico. Na Alemanha, pela forte ascendência da doutrina católica no que se refere à difusão deste princípio, a vigência da subsidiariedade adquire conotação diferente da concepção plenamente liberal.

O catolicismo social al emão delimitou seu campo político em contraposição tanto ao liberalismo, como ao socialismo (Sachsse, 1994: 725). Como a igreja exerceu influência na conformação do próprio Estado Social, a subsidiariedade serviu para enfatizar que o Estado somente interferiria quando a capacidade da família estivesse exaurida (Esping-Andersen, 1990: 27). Embora há muito difundido pela doutrina católica, o termo apenas foi explicitamente referido na Encíclica Social Quadragesimo Anno, de 1931, em contexto de avanço do socialismo e de expansão de doutrinas totalitárias na Europa (Baumgartner, 1997).

Na formulação clássica dessa Encíclica, subsidiariedade é princípio de equilíbrio no campo de tensão entre a intervenção estatal e a liberdade societal. A liberdade de iniciativa individual é afirmada e a intervenção estatal é considerada como de apoio, subsidiária às iniciativas individuais ou de grupos subordinados. “O quecada um a partir desua própria iniciativa e com suas próprias forças pode produzir-conseguir não l he deve ser subtraído e destinado à atividade da Sociedade (Estado), pois deste modo repudia-sea justiça. O queas coletividades pequenas e sub-ordenadas podem fazer elevar a bom cabo ser tomado como direi to das demais comunidades sobre-ordenadas, é si multaneamente e antes de tudo, prejudicial e perturba toda a ordem social. A atividadeda sociedade (Estado) é em sua essência e concei to subsidiária: ela deve apoiar os membros do corpo social, mas nunca lheé permitido destroçá-los ou absorvê-los." (Quadragesimo Anno, 1931, apud Baumgartner, 1997:35; Quadragesimo Anno, 1931, apud Deppe, 1985:84.)

Assim, o Estado não deveria subtrair às famílias as tarefas que elas mesmas estão em condições de preencher. A auto-ajuda deveria ser promovida e possibilitada. E, após uma bem-sucedida 'ajuda para a auto-ajuda', a comunidade/ Estado deveria novamente retirarse (Schönig, 1996:102). Além disso, para a igre- ja católica, a subsidiariedade seria o corretivo contra o excessivo coletivismo: "a arma eo muro de proteção contra tudo o que o col etivismo é, e o queleva ao coletivismo" (Nell-Breuning, 1955, apud Deppe, 1985:84).

Na concepção da doutrina católica, a sociedade é composta organicamente por variado conjunto de coletividades dispostas em círculos ou cascas concêntricas (como uma cebola). Cada coletividade menor teria, frente às maiores, a responsabilidade primeira pela conformação de vida de seus membros. Um possível entendimento seria o seguinte: antes de tudo, o indivíduo deve se auto-ajudar; quando ele tiver esgotado esta possibilidade, a família deve auxiliá-lo; unicamente depois de efetuado este apoio é que deve atuar o município, para então interferir o estado e, posteriormente, a união (Frerich, 1996:32).

Para outros representantes da doutrina social católica, no entanto, o princípio de subsidiariedade não afirma incondicionalmente que os indivíduos e as pequenas comunidades devam atuar primeiro e, somente após terem esgotado todas as suas forças, é que a sociedade e o Estado devem intervir. Estes reformistas sociais católicos defendem que, antes que homens e mulheres possam colocar suas próprias forças em movimento, é necessário que a sociedade já tenha realizado uma série de medidas (Nell-Breuning, 1957, apud Engelhardt, 1994:740). Os riscos sociais não podem ser combatidos apenas pelo indivíduo; a sociedade tem que garantir condições prévias para a promoção de cada um. Mais que assegurar igualdade de oportunidades, esta intervenção seria uma 'ajuda para a auto-ajuda'. No dito “não dê ao pobre o peixe, ensine-o a pescar", se fossem enfatizadas as tais condições, a frase completa seria: promova os meios para que possa adquirir e manejar os instrumentos de pesca.

Esta é a reformulação da concepção de subsidiariedade da doutrina cristã alemã efetuada no final dos anos 50 por Nell-Breuning. Segundo este reconhecido representante da doutrina social católica, a sociedade/ Estado deve garantir as precondições para auto-ajuda. Para que o indivíduo possa empregar suas forças com êxito, torna-se necessária uma série de medidas prévias por parte do Estado. Além disso, as coletividades menores teriam também o direito a reivindicar auxílio às coletividades sobreordenadas.

Ao mesmo tempo, para a doutrina social católica, subsidiariedade e solidariedade não são noções contraditórias. O princípio da subsidiariedade pode ser entendido como contrário ao princípio da solidariedade, em virtude 
de o primeiro representar o pensamento liberal - no qual a intervenção do Estado deve se dar apenas nos caso em que o indivíduo não possa suprir sua necessidade no mercado -, e o segundo, o valor socialista, de igualdade - em que a redistribuição objetiva a equalização de benefícios líquidos individuais (Pereira, 1990: 413). Entretanto, na acepção da doutrina social católica, o princípio da subsidiariedade seria imanente à idéia de solidariedade, pois a subsidiariedade enfatiza a auto-responsabilidade do indivíduo não apenas por si mesmo, mas também pelo conjunto da comunidade solidária à qual pertence (Frerich, 1996:32; Baumgartner, 1997:32).

O pensamento social católico diferencia-se do liberal clássico nesta ênfase da necessidade de o Estado garantir as precondições para a promoção do desenvolvimento das potencialidades de cada família, no direito das comunidades menores em relação às maiores e na consideração da família e não do indivíduo como núcleo social básico (Deppe, 1985; Sachsse, 1994). Estas são as características imprimidas ao princípio de subsidiariedade na conformação da proteção social alemã em razão da influência da igreja católica. A questão da solução das necessidades via mercado, embora presente pelo lado liberal, teve menor destaque.

O debate sobre a subsidiariedade no transcorrer do século 20 assumiu diferentes ênfases. Em geral, este debate foi mais voltado para a questão da assistência social, em que a igreja tem tradicionalmente maior participação por meio das suas entidades filantrópicas, mas atualmente adquire também relevância para a área da saúde - em especial, por causa da influência do neoliberalismo.

Contemporaneamente, alguns autores levantam a necessidade do debate de nova subsidiariedade, a qual objetivaria a substituição da condução externa regulativa por uma autocondução situacional (Sachsse, 1994:734; Wilke, 1996). Assim, a subsidiariedade descreveria a relação entre subsistemas autônomos autoreferenciados, que não conhecem nem ponta nem centro (Luhmann, 1981, apud Sachsse, 1994:734).

No debate acadêmico atual, na área da saúde, podem-se observar duas concepções distintas para a subsidiariedade. Uma, que defende entendimento mais restrito e apela para a auto-responsabilidade dos indivíduos (Schulemburg, 1990; Arnold, 1993). Estes devem, antes de tudo, auto-ajudar-se e solicitar o apoio de sua família para depois recorrer aos benefícios sociais do Estado. Outra corrente, preocupada com a manutenção de um sistema solidá- rio, retoma as formulações sobre subsi diariedade do político social católico Nell Breuning. Para este reformador social católico, como mencionado acima, a sociedade deve criar condições e pressupostos sob os quais cada indivíduo possa exaurir as próprias possibilidades. Nesta concepção, subsidiariedade deixa de ser antagônica à solidariedade, e as ações devem ser prestadas por aquelas instituições consideradas como mais adequadas para tal (Reiners, 1987).

Por conseguinte, nessa linha de pensamento, a forma atual do seguro social de doença é o sistema mais adequado para uma 'economia social de mercado' (denominação atribuída ao modelo alemão pelos democratas-cristãos). A pluralidade de Caixas, com sua especificidade para algumas profissões, seria expressão da subsidiariedade. Caixas diferenciadas corresponderiam a exigências de determinadas regiões ou profissões. Os mineiros e agricultores, por exemplo, possuem Caixas próprias, com condições especiais de financiamento e subsídio estatal direto.

Nos anos 90, o debate sobre o princípio da subsidiariedade, em especial na área da saúde, foi revitalizado. Atualmente, pode-se dizer que o fortalecimento do princípio de subsidiariedade - expresso em todas as proposições de estímulo à auto-responsabilidade - corresponde à premissa neoliberal de mais mercado/menos Estado.

Privatização de riscos, seletividade e focalização - princípios neoliberais para a área social - são defendidos tendo por fundamento a subsidiariedade da intervenção estatal. Subsidiariedade é o princípio básico da política social focal. Política focal é, em essência, o conjunto de medidas definido para minorar os problemas sociais apenas de extratos populacionais mais expostos aos riscos, selecionados com base em algum critério.

No debate atual, a defesa da subsidiariedade significa a retirada da garantia de asseguramento coletivo de riscos, tanto pela diminuição da participação estatal, quanto mediante a redução da parcela da provisão garantida solidariamente via seguro social.

De todo modo, o recurso à subsidiariedade não leva necessariamente à completa retirada do Estado. Embora o apelo atual para auto-responsabilidade em nome da subsidiariedade tenha como propósito limitar e/ ou dispensar a ajuda estatal, subsidiariedade, mesmo em seu sentido mínimo, tem dupla implicação. Ao mesmo tempo que a intervenção estatal deve ser apenas complementar, a vigência da subsidiariedade significa que o Estado intervém em al- 
guma medida. Assim, apelar à subsidiariedade significa rediscutir a 'justa' medida da intervenção estatal e não a retirada do Estado.

\section{Considerações finais}

Como vimos nos tópicos anteriores, no modelo de seguro social, a centralidade no trabal ho assalariado implica que características das relações do mercado de trabal ho sejam transpostas para a base da política social, cristalizando desigualdades, mas, ao mesmo tempo, o Estado Social nega parcialmente os mecanismos de mercado ao assegurar a satisfação de necessidades sociais politicamente definidas. Neste modelo de proteção, o objeto das disputas políticas - o conflito básico - está na adequação entre mérito e necessidade, isto é, em que medida os direitos sociais devem corresponder às necessidades de cada indivíduo ou ao seu mérito.

Embora estruturado com base no mérito, uma concepção de distribuição está embutida em diversas áreas do seguro social. Necessidades politicamente definidas fazem parte da estruturação do sistema, e, uma vez que o princípio da necessidade também se faz valer, independente da capacidade contributiva do indivíduo, a solidariedade toma força no interior do sistema. O princípio de justiça distributiva conforme as necessi dades presente no sistema de seguro social, não deve assim ser subestimado.

Há uma constante tensão entre os princípios constitutivos do seguro social - equivalência/ mérito, solidariedade/ necessidade e subsidiariedade. A vigência plena dos princípios de equivalência e subsi diariedade é contraditória ao exercício da solidariedade. Ao passo que a solidariedade pressupõe alguma redistribuição, a equivalência dos benefícios às contribuições - o direito a benefícios conforme o ‘mérito' - nega esta possibilidade, e a subsidiariedade restringe a comunidade solidária. A solução encontrada para este conflito, assim como para as contradições inerentes ao somatório dos elementos - de natureza distinta - civil, político e social da cidadania (Fleury, 1997:38), resulta da correlação de forças em cada momento (Esping-Andersen, 1990). O ponto de equilíbrio temporário entre a solidariedade e a subsidiariedade, bem como entre a solidariedade e a equivalência, é politicamente definido em cada conjuntura.

No seguro social de doença, impera o princípio da necessidade. Ao garantir a todos os segurados a utilização de serviços de saúde con- forme a necessidade e independente do valor das contribuições, o seguro social de saúde subsume a equivalência à solidariedade. A precedência do princípio da necessidade sobre o princípio da equivalência atenua as características conservadoras do modelo de seguro social alemão de cristalização das desigualdades produzidas pela participação no mercado de trabalho. Além disso, a expansão e a uniformização do catálogo de serviços e benefícios e a progressiva inclusão de camadas cada vez mais abrangentes da população - acoplada às possibilidades de emprego quase pleno - deram feição fortemente universal ao sistema atual.

Dessa forma, historicamente, com os processos de inclusão e expansão do seguro social de doença, o princípio da solidariedade suplantou os princípios de equivalência e de subsidiariedade. No processo atual de contenção, corre-se, porém, o risco de uma revitalização destes princípios. A tensão sempre existente entre a garantia de proteção conforme o mérito ou a necessidade, e entre a responsabilidade individual e aquela da comunidade solidária, tornou a aumentar.

Atualmente, a discussão sobre a subsidiariedade volta a ter destaque e sua vigência é reatualizada em especial por meio da majoração do co-pagamento. Recentemente (junho de 1997), a coalizão liberal-conservadora no poder, rompendo com a tradição anterior de soluções corporativamente negociadas, fez valer a sua maioria parlamentar e aprovou mecanismos de privatização da demanda, como o forte aumento dos valores de co-pagamento e a abertura da possibilidade de introdução de elementos próprios dos seguros privados: a restituição de despesas, o estabelecimento de franquias e prêmios pela não-utilização.

Embora existam mecanismos que atenuem a participação direta nos gastos pelos usuários pertencentes às camadas de renda mais baixa e ainda que a proporção estimada do co-pagamento no conjunto dos gastos do seguro social de doença alemão, mesmo com os aumentos, permaneça em nível inferior ao de outros países europeus, esta clara opção por mecanismos que penalizam pacientes e segurados de menor renda afeta os princípios básicos do seguro social de doença. Provoca impacto negativo sobre o princípio da solidariedade, sob a alusão de fortalecer a subsidiariedade. Para o aumento da participação dos pacientes nos custos da doença, é evocada a necessidade de fortalecimento da auto-responsabilidade de cada indivíduo, reativando a concepção de subsidiariedade prevalente quando da instituição do seguro doença ao final do século passado. 
Deste modo, contemporaneamente, a tendência é de reforço à subsidiariedade - com base na qual a coação à ampliação da responsabilidade individual concretiza-se na privatização de riscos via co-pagamento -, e há indícios de retorno da equivalência, pois poderá vir a ocorrer um reordenamento dos segurados em Caixas de primeira e segunda classe não mais por profissão, e, sim, por nível de renda. O aprofundamento de desigualdades poderá, assim, vir a ser um dos resultados da competição entre as Caixas, possibilitada pela ampliação da liberdade de escolha das Caixas pelos segurados - definida com a Lei da Estrutura da Saúde de 1993 -, e da introdução de mecanismos do seguro privado como novas opções para estabelecimento de contratos, abertas com as Leis de Reordenação do Seguro Social de Doença de 1997.

\section{Agradecimentos}

A elaboração deste artigo foi possibilitada por bolsa de doutoramento sanduíche concedida pela Capes, com estágio realizado no Institut für Medizinische Soziologie der J. W. Goethe Universität em Frankfurt am Main, entre abril de 1996 e junho de 1997.
Não obstante essas medidas recentes possam vir a afetar de modo negativo o princípio da solidariedade, isto não implica necessariamente o desmantelamento do sistema. Se, por um lado, o seguro social poderá vir a permanecer estável, pois a segmentação e a reprodução de privilégios são intrínsecas a este modelo de proteção social, por outro, a identificação de tendências não significa a sua concretização. O sistema atual mantém uma alta aceitabilidade e, na realidade, embora tenham ocorrido algumas restrições, a proteção social ao risco de adoecer na Alemanha permanece ampla e invejável, garantindo atenção à saúde em todos os níveis de complexidade a $90 \%$ da população.

\section{Referências}

ALBER, J., 1982. Vom Armenhaus zum Wohlfahrtsstaat. Analysen zur Entwicklung der Sozialversicherung in Westeuropa. Frankfurt/Main: Campus Verlag.

ARNOLD, M., 1993. Solidarität 2000. Die medizinische Versorgung und ihre Finanzierung nach der Jahrtausendwende. Stuttgart: Ferdinand Enke Verlag.

BAUMGARTNER, A., 1997. Solidarität und Ehrenamtlichkeit, Subsidiarität und Selbsthilfe. Veraltete Prinzipien der Sozial politik? In: Sozial politik (M. R. Textor, org.), pp. 29-37, München: WestdeutscheVerlag.

BMAS (Bundesministerium für Arbeit und Sozialordnug), 1994. Übersicht über das Sozial recht. (pp.113-211) Bonn: BMAS. 
BRAUN, B., 1995. Health reform in Germany - the discovery of managed and solidaristic competition. In: Health Care in Europe: Competition or Solidarity? (S. Iliffe \& H. U. Deppe, eds.), pp. 41-46, Frankfurt am Main: Verlag für Akademische Schriften.

BRD (Bundesrepublik Deutschland), 1993. SGB Sozial gesetzbuch. Reichsversicherungsordnung. 20. Auflage 1993. München: Beck-Texte im DTV.

DEPPE, H. U., 1985. Selbsthilfe zwischen Subsidiarität und Klassensolidarität. Österrei chische Zeitschrift für Sozi ol ogie, 10. Jahrgang, Heft 3-4:82-95.

ENGELHARDT, W. W., 1994. Soziale Sicherung und Subsidiarität. Zeitschrift für Sozialreform. 40. Jahrgang, Heft 11:739-745.

ESPING-ANDERSEN, G., 1990. The Three Worlds of Welfare Capitalism. Cambridge: Polity Press.

FLEURY, S., 1994. Estados sem Cidadãos: Seguridade Social na América Latina. Rio de Janeiro: Ed. Fiocruz.

FLEURY, S., 1997. A questão democrática na saúde. In: Saúde e Democracia: A Luta do Cebes (S. Fleury, org.), pp. 25-44, São Paulo: Lemos.

FRERICH, J., 1996. Sozialpolitik: das Sozialleistungssystem der Bundesrepublik Deutschland, Darstellung, Probleme und Perspektiven der sozialen Sicherung. München: Oldenbourg Verlag.

$\mathrm{KOCH}, \mathrm{C} ., 1995$. Sozialstaat und Wohlfahrtsstaat. Leviathan, 23:79-86.

LAUER-KIRSCHBAUM , T. \& RÜB, F. W., 1994. Politik mit dem Risiko: Der politische Risikoausgleich bei Krankheit. In: Krankheit und Gemeinwohl. Gesundheit zwischen Staat, Sozialversicherung und Medizin (B. Blanke, org.), pp. 37-73, Opladen: Leske +Budrich.

NULLMEIER, F. \& VOBRUBA, G., 1995. Gerechtigkeit in sozialpolitischen Diskurs. In: Gerechtigkeit im Wohlfahrtsstaat (D. Döring, G. F. Nullmeier, R. Pioch \& G. Vobruba, org.), pp. 11-66, Marburg: Schüren.

OFFE, C., 1984. Problemas Estruturais do Estado Capitalista. Rio de Janeiro: Tempo Brasileiro.

OFFE, C., 1990. Akzeptanz und Legitimität Strategischer Optionen in der Sozialpolitik. In: Sicherheit und Frei heit. Zur Ethik desWohlfahrtsstaates (C. Sachsse \& H. T. Engelhardt, org.), pp. 179-202, Frankfurt am Main: Suhrkamp Taschenbuch Wissenschaft.

OLDIGEN, F. J., 1994. Generationenvertrag noch Stabil? Renten und Krankenversicherung betroffen. D. O. K. 76Jahrgang, Heft 3:73-75.

OLIVEIRA, C. R., 1995. O Labirinto Social ou Farewell, Welfare. A Constituição Histórica do Seguro Social na Alemanha (1871-1932). Tese de Doutorado, Rio de Janeiro: Escola Nacional de Saúde Pública, Fundação Oswaldo Cruz.
PEREIRA, J., 1990. Justiça social no domínio da saúde Cadernos de Saúde Pública, 6:400-421.

REINERS, H., 1987. Ordnungspolitik im Gesundheitswesen - Ausgangspunkte und Konzepte. WIdO-Materialien, Band 30. Bonn: Wissenschatliches Institut der Ortskrankenkassen.

RINNE, K. \& WAGNER, G., 1995. Droht ein “Krieg der Generationen"? Empirische Evidenz zur Zufriedenheit mit der Sozialen Sicherung. Sozialer Fortschritt, 12:288-295.

SACHSSE, C., 1994. Subsidiarität: Zur Karriere eines sozialpolitischen Ordnungsbegriffes. Zeitschrift für Sozial reform, 40. Jahrgang, Heft 11:717-738.

SANTOS, W. G., 1979. Cidadania eJustiça. A Política Social na Ordem Brasileira. Rio de Janeiro: Campus.

SCHÖNIG, W. 1996. Zur Zukunft der Prinzipien sozialer Sicherung. In: Sozialstaat wohin?: Umbau, Abbau oder Ausbau der sozialen Sicherung (W. Schönig \& R. L'Hoest, org.), pp. 101-118, Darmstadt: Wissenschaftliche Buchgesellschaft.

SCHULEMBURG, J. M. G. V. D., 1990. Die etische Grundlagen des Gesunheitssystems in der Bundesrepublik Deutschland: Versuch einer Positionsbestimmung. In: Sicherheit und Frei heit zur Ethik desWohlfahrtsstaates (C. Sachsse \& H. T. Engelhardt, org.), pp. 313-335, Frankfurt am Main: Suhrkamp.

SVR (Sachverständigenrat für die Konzertierte Aktion im Gesundheitswesen), 1994. Gesundheitsversorgung und Krankenversicherung 2000: Eigenverantwortung, Subsidiarität und Solidarität bei sich änderden Rahmenbedingungen. Sachstandsbericht 1994. Baden-Baden: Nomos Verlagsgesellschaft.

TITMUSS, R., 1958. Essays on the Welfare State. London: George Allen and Unwin.

ULRICH, C. G.; WEMKEN, I. \& WALTER, H., 1994. Leistungen und Beiträge als determinanten der Zufriedenheit mit der Gesetzlichen Krankenversicherung: Ergebnisse einer empirischen Untersuchung zur Akzeptanz des Krankenversicherungssystems bei den gesetzlich Versicherten. Zeitschrift für Sozial reform, 40:349-375.

WERNECK VIANNA, M. L. T., 1991. Notas sobre política social. Physis, 1:133-157.

WILKE, H., 1996. Die Steuerungsfunktion des Staates aus systemtheoretischer Sicht. In: Staatsaufgabe (D. Grimm, org.), pp. 313-335, Frankfurt: Suhrkamp Taschenbuch. 